\title{
MicroRNA-449a inhibits cell proliferation and migration by regulating mutant p53 in MDA-MB-468 cells
}

\author{
GUANGCHENG HUANG ${ }^{1 *}$, XIAOWU ZHONG ${ }^{1-3^{*}}$, LIHUA YAO ${ }^{1}$, QIANG MA $^{1}$, HEBIN LIAO ${ }^{2}$, \\ LEI XU ${ }^{2}$, JIANG ZOU $^{3}$, RU SUN ${ }^{3}$, DONGSHENG WANG ${ }^{3}$ and XIAOLAN GUO ${ }^{1-3}$ \\ ${ }^{1}$ Department of Clinical Laboratory, Affiliated Hospital of North Sichuan Medical College, Nanchong, \\ Sichuan 637000; ${ }^{2}$ Translational Medicine Research Center; ${ }^{3}$ Department of Laboratory Medicine, \\ North Sichuan Medical College, Nanchong, Sichuan 637007, P.R. China
}

Received February 27, 2020; Accepted January 18, 2021

DOI: $10.3892 / \mathrm{etm} .2021 .10452$

\begin{abstract}
The present study aimed to investigate the role of microRNA (miR)-449a in the proliferation, migration and apoptosis of MDA-MB-468 breast cancer cells and examine the association between miR-449a and mutant p53 in these cells. Cell proliferation, migration and invasion were examined using a crystal violet staining assay, wound healing scratch assay and Transwell assay, respectively. The expression level of miR-449a and p53 was detected by reverse transcription-quantitative PCR or western blotting. The results indicated that knockdown of mutant p53 suppressed the proliferation and migration of MDA-MB-468 cells by inhibiting the $\mathrm{PI} 3 \mathrm{~K} / \mathrm{AKT} / \mathrm{mTOR}$ signaling pathway. In addition, miR-449a suppressed proliferation and migration via downregulation of mutant p53 expression in MDA-MB-468 cells. Therefore, miR-449a may function as a tumor suppressor by regulating p53 expression in breast cancer cells, which may have potential implications in the treatment of patients with triple-negative breast cancer carrying mutant p53.
\end{abstract}

\section{Introduction}

Breast cancer is the most common cancer and the leading cause of cancer-associated mortality among females worldwide $(1,2)$. Triple-negative breast cancer (TNBC) is characterized by a lack of expression of estrogen receptor (ER), progesterone receptor (PR) and human epidermal growth factor receptor 2 (HER2). Owing to the early metastasis and a lack of available therapeutic targets, patients suffering from TNBC have

Correspondence to: Professor Xiaolan Guo, Department of Clinical Laboratory, Affiliated Hospital of North Sichuan Medical College, 39 Wenhua Road, Nanchong, Sichuan 637000, P.R. China

E-mail: alan5200@hotmail.com

"Contributed equally

Key words: breast cancer, triple-negative breast cancer, microRNA-449a, mutant p53, downregulation been reported to exhibit a poor prognosis and low survival rate compared with most of other types breast cancer $(3,4)$, indicating a requirement to identify novel biomarkers for the early diagnosis of TNBC, as well as potential molecular targets and novel treatment strategies (5).

In TNBC, p53 is the most frequently mutated gene, the mutation rate is as high as $80 \%$ (6). Mutant p53 lacks the wild-type tumor-suppressor activity of p53 and acts as an oncogene via gain-of-function activities, including induction of cell proliferation, invasion, migration and inhibition of cell apoptosis, which promote increased aggressiveness in cancer cells (7-9).

MicroRNAs (miRNAs/miRs) are a class of small non-coding RNAs with 22 nucleotides, which regulate gene expression by interacting with a number of proteins to form an RNA-induced silencing complex, which subsequently targets and binds to the 3'-untranslated region of target mRNAs to mediate mRNA degradation or translational repression (10). Previous studies have reported the dysregulation of miRNAs in various cancer cells and demonstrated that this dysregulation may be associated with tumorigenesis, cancer progression, migration and invasion (11-14).

A previous study revealed that miR-449a was downregulated in breast cancer tissues, especially in TNBC tissues from patients carrying mutant p53 (15). miR-449a has been indicated to reduce the growth of cancer cells via targeting and inhibiting the expression of histone deacetylase 1 , which is involved in maintaining the expression of mutant p53 (16-18). Furthermore, miR-449a has been reported to act as a tumor suppressor in colorectal cancer, hepatocellular carcinoma, non-small cell lung cancer and gastric adenocarcinoma (19-22). However, the role of miR-449a in breast cancer and its associated mechanisms, especially in TNBC harboring mutant $\mathrm{p} 53$, are yet to be elucidated.

In the present study, the role of miR-449a in the proliferation, migration and apoptosis of MDA-MB-468 breast cancer cells was investigated. The cellular signaling pathway of p53 and the association of miR-449a with mutant p53 in MDA-MB-468 cells were also examined.

\section{Materials and methods}

Cell culture, transfection and infection. 293T cells were purchased from ATCC, human normal mammary epithelial 
cells MCF-10A and TNBC cell lines with p53 mutation [MDA-MB-468 (R273H) and MDA-MB-231 (R280K)] were obtained from the Department of Laboratory Medicine, Chongqing Medical University (Chongqing, China). All the cells were cultured in DMEM (Gibco; Thermo Fisher Scientific, Inc.) supplemented with 10\% FBS (Gibco; Thermo Fisher Scientific, Inc.), at $37^{\circ} \mathrm{C}$ with $5 \% \mathrm{CO}_{2}$. The retroviral pSuper-Retro-puro-short hairpin (sh)-hp53 vector donated by the Hormel Institute of the University of Minnesota was used to knock-down p53 expression. $2 \times 10^{6} 293 \mathrm{~T}$ cells were seeded into $6 \mathrm{~cm}$ dish, pSuper-Retro-puro-sh-hp53 (3 $\mu \mathrm{g})$ or pSuper-Retro-puro- sh-vector $(3 \mu \mathrm{g})$ was co-transfected with the packaging plasmid pAmpho $(1.5 \mu \mathrm{g})$ into $293 \mathrm{~T}$ cells using Lipofectamine ${ }^{\circledR} 2000$ reagent (Invitrogen; Thermo Fisher Scientific, Inc.), the retroviruses were harvested from medium supernatant at 48 and $72 \mathrm{~h}$. The MDA-MB-468 cells infected by retroviral supernatant $\left(6 \times 10^{8} \mathrm{MOI} / \mathrm{ml}\right)$ for $72 \mathrm{~h}$, then treated by $1.5 \mu \mathrm{g} / \mathrm{ml}$ puromycin for 2 weeks to obtain stably transfected cells. MDA-MB-468 cells were transfected with miR-449a-mimic or miR-449a-NC (100 nM; designed and synthesized by Guangzhou RiboBio Co., Ltd.) for $8 \mathrm{~h}$ using Lipofectamine ${ }^{\circledR} 2000$ reagent, and all the subsequent experimentations were completed within $96 \mathrm{~h}$.

$R N A$ extraction and reverse transcription-quantitative PCR $(R T-q P C R)$. Total RNA was extracted from MDA-MB-468, MDA-MB-231 and MCF-10A cells using TRIzol ${ }^{\circledR}$ reagent (Invitrogen; Thermo Fisher Scientific, Inc.) according to the manufacturer's protocol. RNA $(1.8 \mu \mathrm{g})$ and M-MLV reverse transcriptase (Promega Corporation) were used to synthesize first-strand cDNA, according to the manufacturer's protocol. For miRNA reverse transcription, specific stem-loop primers were used. qPCR was carried out using FastStart Essential DNA Green Master kit (Roche Diagnostics) by the manufacturer's protocol. The thermocycling conditions for qPCR were as follows: $10 \mathrm{~min}$ at $95^{\circ} \mathrm{C}$, and then 40 cycles of $30 \mathrm{sec}$ at $95^{\circ} \mathrm{C}$, $30 \mathrm{sec}$ at $60^{\circ} \mathrm{C}\left(62^{\circ} \mathrm{C}\right.$ for p53 and miR-449a) and the $2^{-\Delta \Delta \mathrm{Cq}}(23)$ method was used to calculate the relative expression level of miR-449a, p53, E-cadherin, Vimentin, Twist and Snail. GAPDH and U6 were used as control genes for mRNA and miR-449a expression detection, respectively. The primers (Table I) used for PCR were synthesized by Sangon Biotech Co., Ltd.

Western blot assay. MDA-MB-468, MAD-MB-231 and MCF-10A cells were lysed with NP-40 lysis buffer (Beyotime Institute of Biotechnology) to extract total proteins, and a BCA kit (Thermo Fisher Scientific, Inc.) was used to determine the protein concentration. A total of $40 \mu \mathrm{g}$ protein was separated by $10 \%$ SDS-PAGE ( $8 \%$ for mTOR and p-mTOR) and transferred to a PVDF membrane (Bio-Rad Laboratories Inc.). The membrane was blocked with $5 \%$ non-fat milk for $1 \mathrm{~h}$ at room temperature. The primary antibodies were diluted to 1:1,000 and incubated with the PVDF membrane overnight at $4^{\circ} \mathrm{C}$. The secondary antibody was diluted to $1: 3,000$ and incubated PVDF membrane for $1 \mathrm{~h}$ at room temperature. The primary antibodies specific to p53 (cat. no. 2527), AKT1 (cat. no. 2938), phosphorylated (p)-AKT (cat. no. 4060), m-TOR (cat. no. 2983), p-mTOR (cat. no. 2971), Bcl-2 (cat. no. 4223), caspase-3 (cat. no. 14220), cleaved caspase-3 (cat. no. 9661) and GAPDH (cat. no. 2118) and the secondary antibody Anti-rabbit IgG (cat. no. 7074) were purchased from Cell Signaling Technology, Inc. The proteins were visualized using an ECL reagent kit (EMD Millipore) using Vilber fusion FX7 spectra chemiluminescence apparatus (Vilber Lourmat).

Cell migration assays. Transwell migration and wound healing assays were carried out to assess the cell migratory ability. For the Transwell migration assay, Transwell chambers (pore size, $6.5 \mathrm{~mm}$ ) were put into 24-well plates, a total of $1 \times 10^{5}$ MDA-MB-468 cells resuspended in $200 \mu \mathrm{l}$ serum-free DMEM were placed into the upper Transwell chamber (Corning, Inc.), and $600 \mu \mathrm{l}$ DMEM with 10\% FBS was added into the lower chamber. After $24 \mathrm{~h}$, the cells in the upper chamber were removed using a cotton swab, and the cells on the surface of the lower chamber membrane were fixed by $4 \%$ paraformaldehyde for $15 \mathrm{~min}$ and stained with $0.1 \%$ crystal violet for $20 \mathrm{~min}$ at room temperature. Image acquiring and cells counting were performed with BX51 light microscope (Olympus Corporation) at magnification of x200 in eight randomly selected fields.

For the wound healing assay, $1.8 \times 10^{6}$ MDA-MB-468 cells resuspended in DMEM with 3\% FBS were seeded into 6-well plates. The scratches were created using a $200 \mu 1$ pipette tip when cells reached $90 \%$ confluency. Then the medium was removed from plate and the plate was washed using PBS to remove non-attached cells, the attached cells were cultured in serum-free DMEM. The width of the scratch was observed and images were captured after $48 \mathrm{~h}$ using a BX51 light microscope at magnification of $\mathrm{x} 100$.

Cell proliferation assay. A growth curve was used to assess cell proliferation. 1 $10^{5}$ MDA-MB-468 cells were seeded into 6-well plates in DMEM supplemented with 10\% FBS. Cell proliferation was evaluated every $24 \mathrm{~h}$ for $96 \mathrm{~h}$. The cells were fixed using $4 \%$ paraformaldehyde for $15 \mathrm{~min}$, then stained using $0.1 \%$ crystal violet for $20 \mathrm{~min}$, before crystal violet-stained cells were decolorized using $10 \%$ acetic acid for $10 \mathrm{~min}$. The OD values of the de-staining solution was detected at $590 \mathrm{~nm}$ to generate a growth curve.

Statistical analysis. All data are presented as the mean \pm SD from at least three independent experiments with similar results. Significant differences were analyzed by Student's t-test (independent two-sample t-test) or one-way ANOVA (followed by Fisher's Least Significant Difference post hoc test) using SPSS v22.0 software (IBM Corp.). P $<0.05$ was considered to indicate a statistically significant difference.

\section{Results}

miR-449a expression level is decreased in MDA-MB-468 cells overexpressing mutant $p 53$. The expression levels of miR-449a and p53 were detected via RT-qPCR. Mutant p53 protein level was determined via western blotting. The results revealed that the expression level of mutant p53 was significantly higher in MDA-MB-468 and MDA-MB-231 cells compared with that in MCF-10A cells (Fig. 1A and B); However, miR-449a expression level was lower in MDA-MB-468 cells compared with that in MCF-10A cells, but significant higher in MDA-MB-231 cells (Fig. 1C). 
Table I. Primer sequences used in RT-PCR and RT-qPCR.

\begin{tabular}{|c|c|c|c|c|}
\hline Reaction type & Gene & Forward/Reverse primer & Sequence $\left(5^{\prime}-3^{\prime}\right)$ & Product size (bp) \\
\hline \multirow[t]{3}{*}{ RT-PCR } & miR-449a & - & 5'-GTCGTATCCAGTGCAGGGTCCGAG & - \\
\hline & & & GTATTCGCACTGGATACGACACCAGC-3' & \\
\hline & U6 & - & 5'-AACGCTTCACGAATTTGCGT-3' & - \\
\hline \multirow[t]{16}{*}{ RT-qPCR } & $\operatorname{miR}-449 a$ & Forward & 5'-TGCGGTGGCAGTGTATTGTTAGC-3' & 64 \\
\hline & & Reverse & 5'-CCAGTGCAGGGTCCGAGGTA-3' & \\
\hline & U6 & Forward & 5'-CTCGCTTCGGCAGCACA-3' & 94 \\
\hline & & Reverse & 5'-AACGCTTCACGAATTTGCGT-3' & \\
\hline & E-cadherin & Forward & 5'-AATCCCACCACGTACAAGGG-3' & 93 \\
\hline & & Reverse & 5'-GGTATTGGGGGCATCATCAT-3' & \\
\hline & Vimentin & Forward & 5'-TCCAGCAGCTTCCTGTAGGT-3' & 241 \\
\hline & & Reverse & 5'-CCСТCACCTGTGAAGTGGAT-3' & \\
\hline & Twist & Forward & 5'-GACAGTGATTCCCAGACGG-3' & 190 \\
\hline & & Reverse & 5'-GTCCATAGTGATGCCTTTCCT-3' & \\
\hline & Snail & Forward & 5'-TTTACCTTCCAGCAGCCCTA-3' & 108 \\
\hline & & Reverse & 5'-GACAGAGTCCCAGATGAGCA-3' & \\
\hline & p53 & Forward & 5'-CCAGGGCAGCTACGGTTTC-3' & 205 \\
\hline & & Reverse & 5'-CTCCGTCATGTGCTGTGACTG-3' & \\
\hline & GAPDH & Forward & 5'-ACAACTTTGGTATCGTGGAAGG-3' & 101 \\
\hline & & Reverse & 5'-GCCATCACGCCACAGTTTC-3' & \\
\hline
\end{tabular}

RT, reverse transcription; RT-qPCR, RT-quantitative PCR; miR, microRNA.

Overexpression of miR-449a suppresses the proliferation and migration of MDA-MB-468 cells. miR-449a was indicated to be expressed at a low level in MDA-MB-468 cells, as aforementioned. To examine the physiological effects of miR-449a, miR-449a mimic was transfected into MDA-MB-468 cells, and overexpression of miR-449a was validated by RT-qPCR (Fig. 2A). As presented in Fig. 2B and C, overexpression of miR-449a suppressed MDA-MB-468 cell proliferation compared with the miR-NC group. Furthermore, the migratory capacity of MDA-MB-468 cells was inhibited by $\mathrm{miR}-449 \mathrm{a}$ overexpression, as indicated by the results of the Transwell migration (Fig. 2D and E) and wound healing assays (Fig. 2F).

miR-449a reduces the expression of mutant 553 and inhibits the PI3K/AKT/mTOR signaling pathway and epithelial-mesenchymal transition (EMT) in MDA-MB-468 cells. To further explore the molecular mechanisms of miR-449a-mediated biological activities, miR-449a mimic was transfected into MDA-MB-468 cells. As illustrated in Fig. 3A, overexpression of miR-449a reduced the p53 protein level in MDA-MB-468 cells, and the level of the PI3K/AKT/mTOR pathway targets p-AKT and p-mTOR was markedly reduced compared with the miR-NC group. Moreover, the expression level of Bcl-2 and caspase-3 was decreased by miR-449a overexpression, although cleaved caspase-3 expression was not detected (Fig. 3B).

Furthermore, the expression of EMT-related genes was examined by RT-qPCR after miR-449a overexpression, and the results indicated that the expression level of vimentin, Twist and Snail was significantly reduced, while that of E-cadherin was slightly increased compared with miR-NC-transfected cells (Fig. 3C).

Knockdown of mutant p53 suppresses the proliferation and migration of MDA-MB-468 cells. The p53 mRNA and protein were knockdown in MDA-MB-468 cells by retroviral pSuper-Retro-puro- short hairpin (sh)-hp53 vector (Fig. 4A and B). It was revealed that the proliferation of $\mathrm{p} 53$ knocked-down MDA-MB-468 cells was notably inhibited compared with vector-transduced cells (Fig. 4C and D), and the migratory capacity exhibited the same trend (Fig. 4E-G).

Mutant p53 regulates proliferation and migration via the PI3K/AKT/mTOR signaling pathway and EMT in MDA-MB-468 cells. The PI3K/AKT/mTOR pathway has been indicated to regulate the survival, proliferation, invasion and migration of cancer cells (24). In p53 knocked-down MDA-MB-468 cells the protein level of several members of this pathway was detected, and it was observed that the expression level of p-AKT and p-mTOR was remarkably decreased (Fig. 5A), which indicated that the PI3K/AKT/mTOR pathway was inhibited. In addition, apoptosis was examined in p53-depleted cells, and the results indicated that Bcl-2 expression level was decreased, while cleaved caspase-3 expression level was increased compared with vector-transduced cells (Fig. 5B), suggesting that the apoptotic pathway was activated.

In the present study, the expression levels of E-cadherin, vimentin, Twist and Snail were evaluated by RT-qPCR. The results demonstrated that in p53 knocked-down MDA-MB-468 cells, the expression level of E-cadherin was increased, while the expression levels of vimentin, Twist and Snail 
A

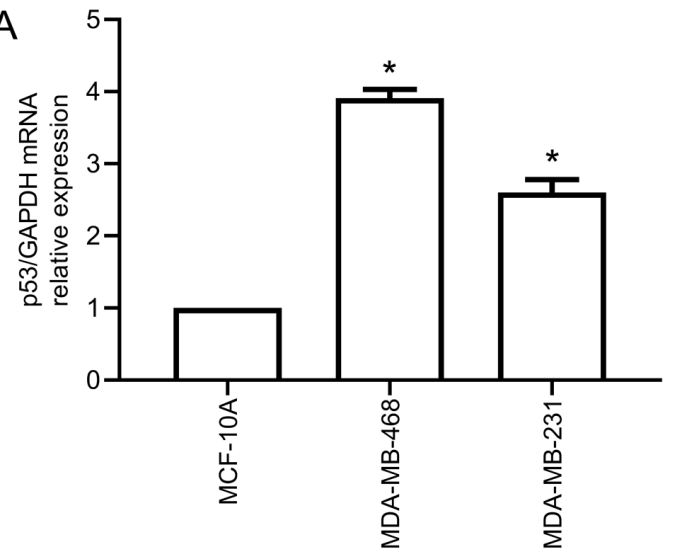

B

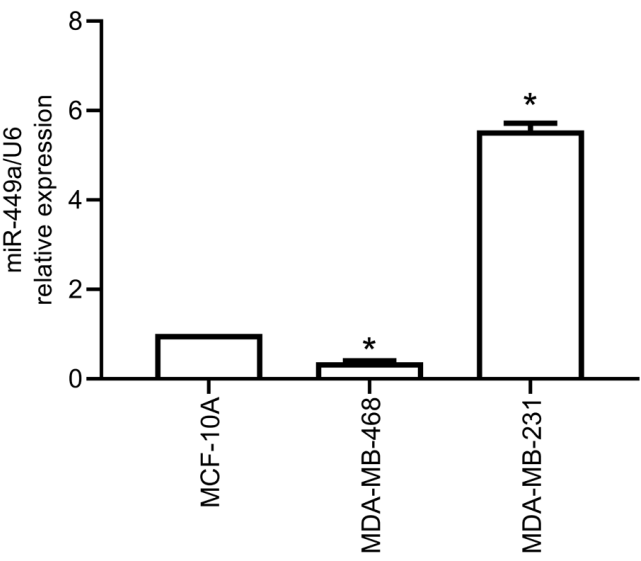

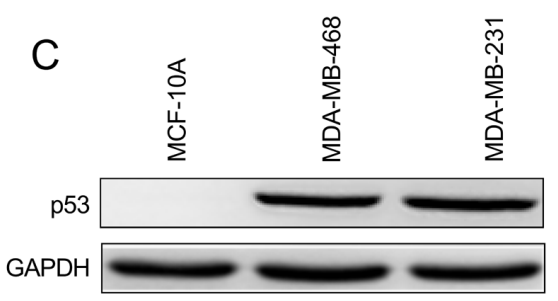

Figure 1. Expression of p53 and miR-449a in breast cancer cells and normal breast epithelial cells. (A) mRNA expression level of p53, (C) protein level of p53 and (B) miR-449a expression level in breast cancer cells and normal breast epithelial cells. Data are presented as the mean \pm SD. ${ }^{*} \mathrm{P}<0.05$ vs. MCF-10A. miR, microRNA.
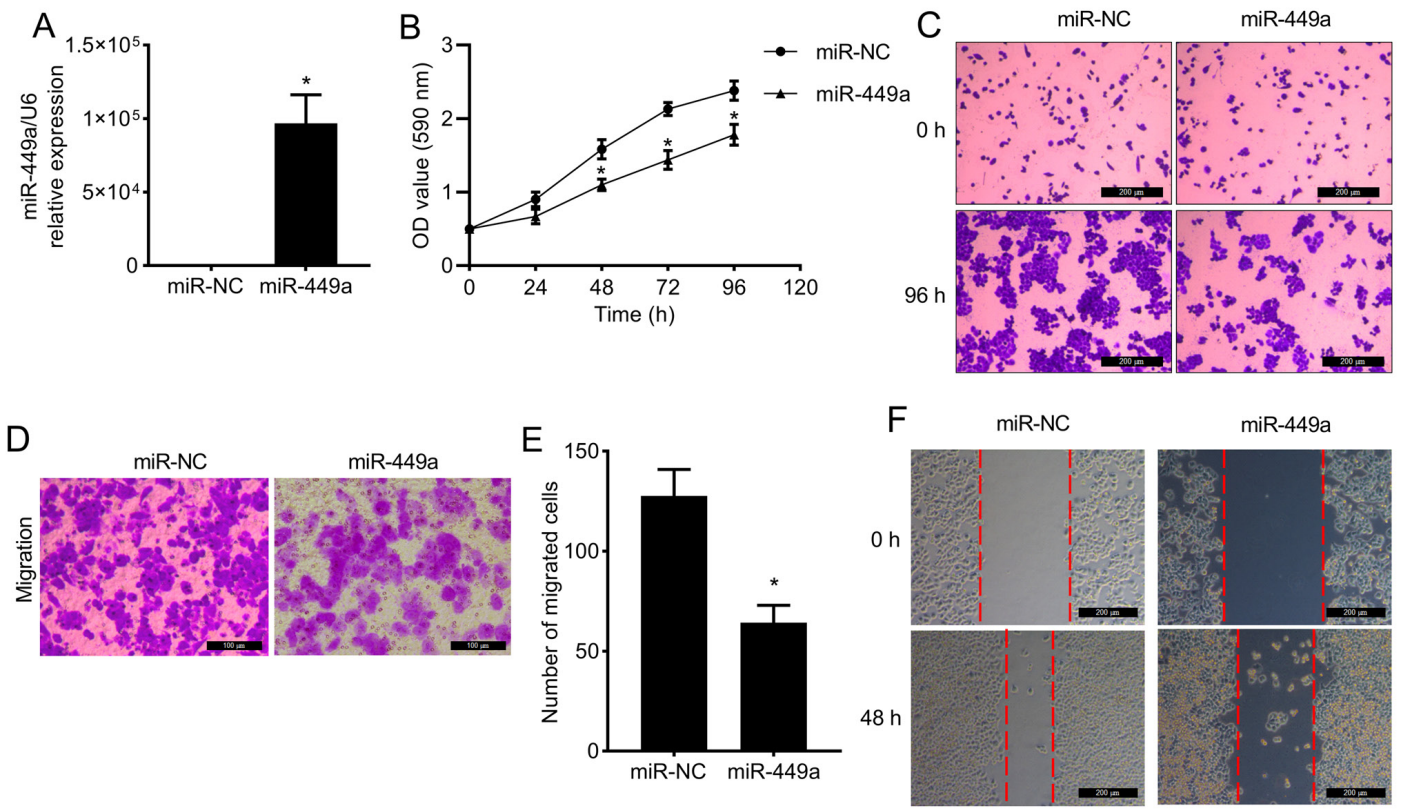

$\operatorname{miR}-449 a$

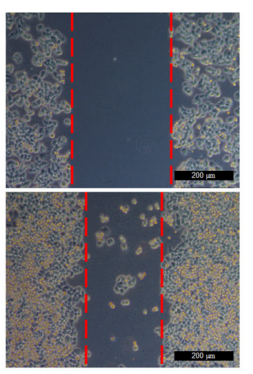

Figure 2. Overexpression of miR-449a suppresses the proliferation and migration of MDA-MB-468 cells. (A) miR-449a level was detected by reverse transcription-quantitative PCR. (B and C) Cell proliferation was assessed by growth curve analysis and representative images were captured at the indicated time points. Cell migration was assessed by (D and E) Transwell assay and (F) wound healing assay. Data are presented as the mean \pm SD. " $\mathrm{P}<0.05 \mathrm{vs}$. miR-NC. miR, microRNA; NC, negative control.

were markedly reduced (Fig. 5C), indicating that EMT was inhibited upon knockdown of mutant p53. On the other hand, miR-449a level was detected in p53 knocked-down cells, while no significant difference was observed in the miR-449a level compared with vector-transduced cells (Fig. 5D). These data collectively suggested that the repressive effects of miR-449a on cell proliferation and migration may be partly facilitated by a decrease in mutant p53 in MDA-MB-468 cells.

\section{Discussion}

p53 is the most extensively studied tumor suppressor gene, and mutant $\mathrm{p} 53$ proteins not only lose their tumor suppressive abilities, but also gain additional oncogenic functions that provide cells with growth and survival advantages (25). Previous studies have demonstrated that restoration of wild-type p53 of colorectal cancer or removing the mutant p53 
A

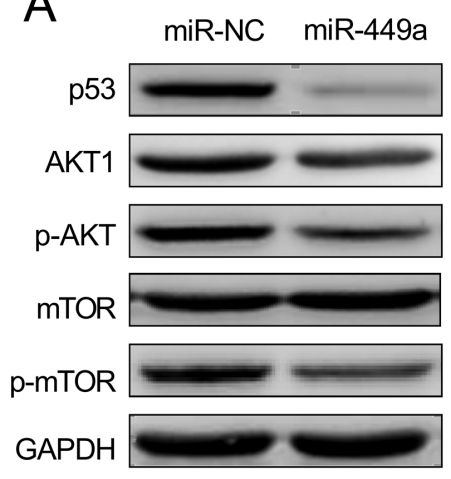

$\mathrm{C}$

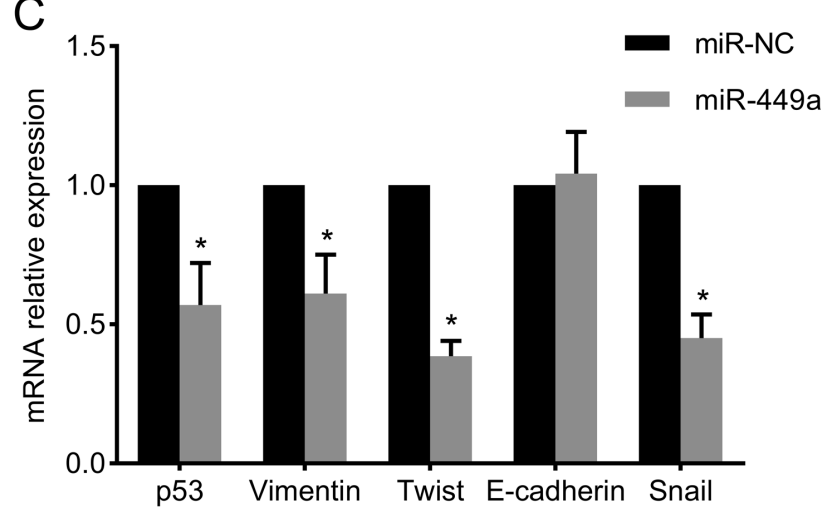

Figure 3. miR-449a reduces the expression of mutant p53 and inhibits the PI3K/AKT/mTOR signaling pathway and EMT in MDA-MB-468 cells. (A) Expression level of PI3K/AKT/mTOR signaling pathway proteins, (B) protein expression level of Bcl-2 and caspase-3 and (C) mRNA expression level of EMT-associated genes in MDA-MB-468 cells transfected with miR-449a mimic or miR-NC. "P<0.05 vs. miR-NC. miR, microRNA; NC, negative control; EMT, epithelial-mesenchymal transition; p-, phosphorylated.

from a mutant p53 oncogene addiction mice model were help for cancer therapy $(26,27)$.

In the current study, it was indicated that the reduction of mutant p53 expression level effectively suppressed the proliferation and migration of MDA-MB-468 cells. Subsequent analysis revealed that the $\mathrm{PI} 3 \mathrm{~K} / \mathrm{AKT} / \mathrm{mTOR}$ signaling pathway was notably downregulated by the knockdown of mutant p53. The PI3K/AKT/mTOR signaling pathway is involved in cell proliferation, survival, apoptosis and migration (24). Therefore, it can be concluded that mutant p53 regulates the PI3K/AKT/mTOR signaling pathway in MDA-MB-468 cells and decreasing mutant p53 expression level may suppress cell proliferation and migration by inhibiting the PI3K/AKT/mTOR signaling pathway.

EMT represents a process that results in a complete loss of epithelial traits in epithelial cells accompanied by the acquisition of mesenchymal traits. More specifically, epithelial cell layers lose their polarity and the cell-cell contacts while undergoing important cytoskeletal remodeling (28). A hallmark of the EMT process is the acquisition of the ability to migrate and invade the extracellular matrix as single cells (29). EMT involves the loss of E-cadherin expression and the acquisition of the expression of the mesenchymal marker vimentin (30). EMT enhances the mobility of cancer cells and drives cancer metastasis (31). A number of studies have demonstrated that mutant p53 can promote EMT (32-34), and in the current study it was revealed that EMT was suppressed by the knockdown of mutant p53, suggesting that downregulation of mutant

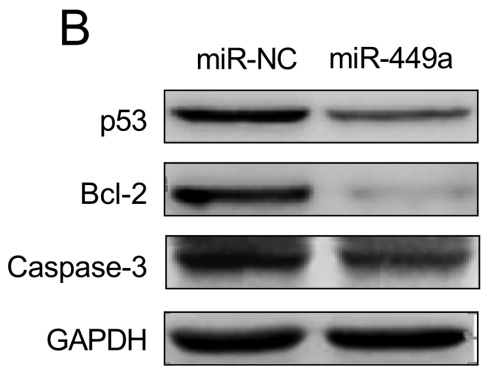

p53 expression may inhibit the migration of cancer cells by suppressing EMT.

The protein expression levels of Bcl-2, caspase-3 and cleaved caspase- 3 , which are indicative of apoptosis, were also detected. Bcl-2 belongs to the Bcl-2 family members that exert both pro- and anti-apoptotic function, and the reduced expression level of Bcl-2 can induce apoptosis in cancer cells (35). Cleaved caspase- 3 is produced by the activation of caspase- 3 and induces cell apoptosis (36). In the present study, knockdown of mutant p53 decreased the expression level of Bcl-2, while that of cleaved caspase- 3 was increased, suggesting that the apoptotic pathway was activated.

In previous studies, miR-449a has been reported to act as a tumor suppressor to inhibit cell migration, metastasis and proliferation and induce cell senescence in NSCLC and prostatic cancer (37-39). However, the function of miR-449a in breast cancer is still controversial $(15,40)$, and the interaction between miR-449a and mutant p53 remains elusive. In the current study, it was demonstrated that overexpression of miR-449a suppressed proliferation and migration of MDA-MB-468 cells, resulting in a similar effect to the knockdown of mutant p53. Subsequent analysis revealed that the expression of mutant p53 was markedly decreased in MDA-MB-468 cells transfected with miR-449a mimic. Additionally, the PI3K/AKT/mTOR pathway and EMT were suppressed following miR-449a overexpression, suggesting that miR-449a may function as a tumor suppressor to inhibit proliferation and migration of breast cancer cells 

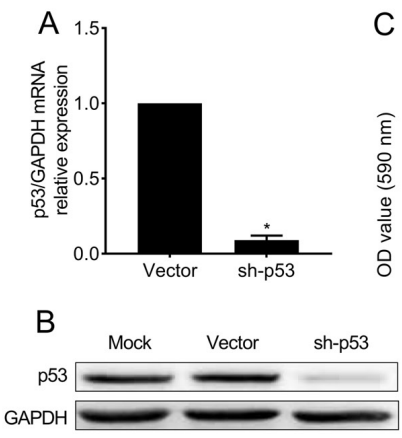

C

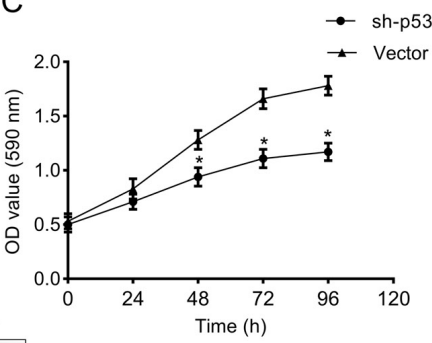

D

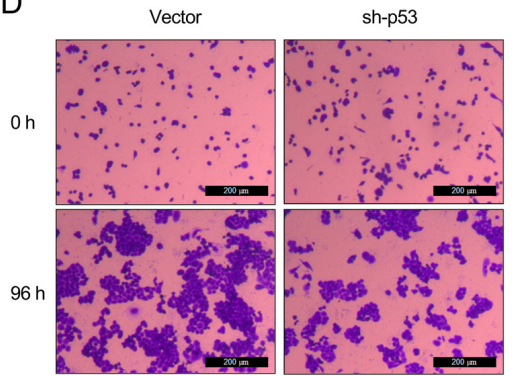

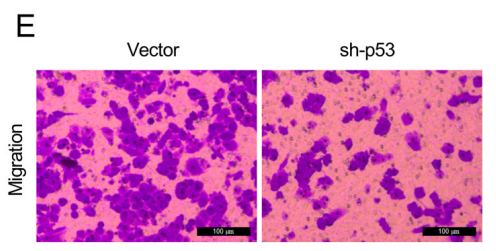
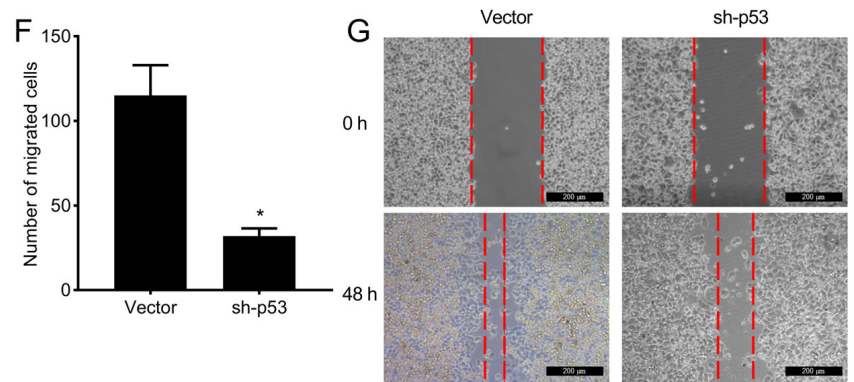

Figure 4. Knockdown of mutant p53 suppresses the proliferative and migratory abilities of MDA-MB-468 cells. (A) p53 expression level was detected by reverse transcription-quantitative PCR after knockdown of mutant p53. (B) p53 protein expression level was detected by western blotting. (C and D) Cell proliferation was assessed by growth curve analysis and representative images were captured at the indicated time points. Cell migration was assessed by (E and F) Transwell assay and (G) wound healing assay. Data are presented as the mean \pm SD. ${ }^{*} \mathrm{P}<0.05$ vs. vector. sh, short hairpin; $\mathrm{p}-$, phosphorylated.
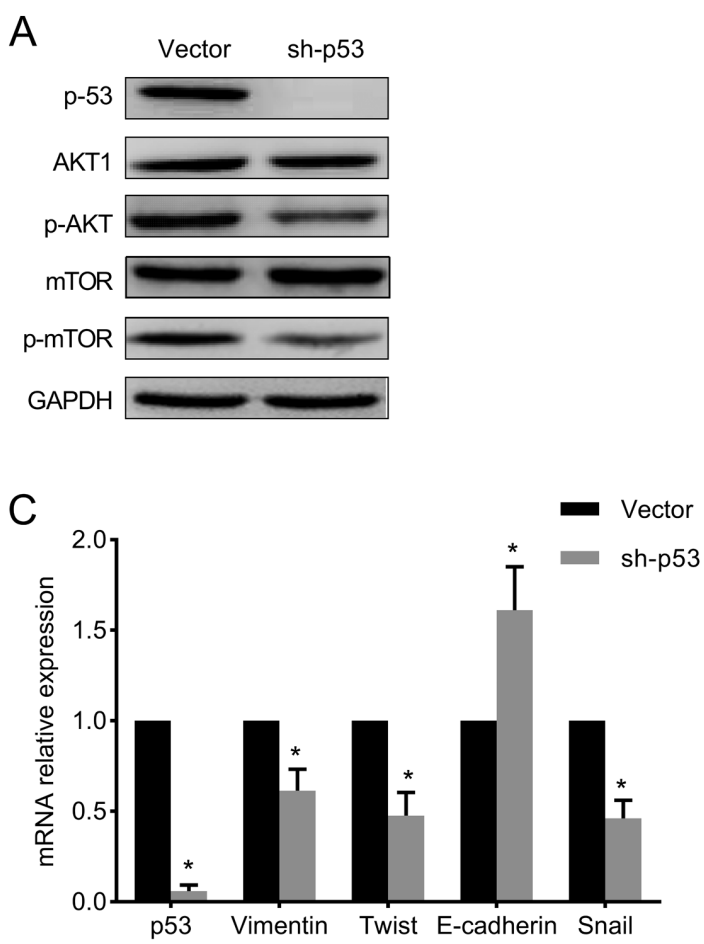
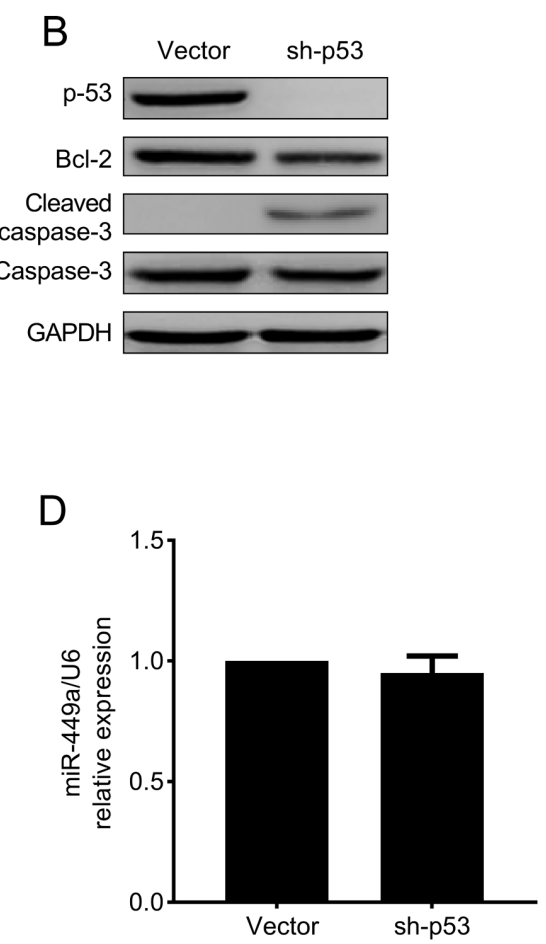

Figure 5. Mutant p53 regulates proliferation and migration via the PI3K/AKT/mTOR signaling pathway and EMT in MDA-MB-468 breast cancer cells. (A) Expression level of PI3K/AKT/mTOR signaling pathway proteins, (B) protein expression level of Bcl-2, caspase-3 and cleaved caspase-3, (C) mRNA expression level of EMT-associated genes and (D) expression level of miR-449a in p53 knocked-down MDA-MB-468 cells. Data are presented as the mean \pm SD; "P<0.05 vs. vector. sh, short hairpin; EMT, epithelial-mesenchymal transition; miR, microRNA; p-, phosphorylated.

via downregulation of mutant $\mathrm{p} 53$. In addition, Bcl-2 expression level was reduced following overexpression of miR-449a, which is consistent with Bcl-2 being previously reported as a target of miR-449a (20). Knockdown of p53 also decreased Bcl-2 expression level, indicating that Bcl-2 expression was regulated by both miR-449a and mutant p53. However, the expression level of cleaved-caspase-3 was not detected in miR-449a-overexpressing cells. Taken together, the aforementioned results suggested that mutant p53 participates in the mechanism of miR-449a function, 
affecting the proliferation and migration of MDA-MB-468 cells.

To verify the results associated with miR-449a in MDA-MB-468 cells, MDA-MB-231 cells overexpressing miR-449a and mutant p53 (R280K) were used. However, the results obtained were not in agreement with those observed in MDA-MB-468 cells. This controversial outcome may be associated with the type of mutant p53 in each cell line.

The present study demonstrated that miR-449a functions as a tumor suppressor to inhibit proliferation and migration and induce apoptosis by downregulating the expression of mutant p53 in MDA-MB-468 breast cancer cells. These results indicated that miR-449a is a key component that targets the p53 pathway, highlighting that inhibiting mutant p53 expression via miR-449a may be a potential therapeutic strategy for TNBC. However, additional experiments are required in future studies. The protein expression of EMT-associated genes should be investigated, the effect of miR-449a on cell apoptosis should be detected via flow cytometry and the level of additional apoptosis-related proteins [cytochrome $c$, Bad, and poly (ADP-ribose) polymerase] should be examined by western blotting.

\section{Acknowledgements}

Not applicable.

\section{Funding}

The present study was supported from Science and Technology Support Program of Nanchong (grant no. 18SXHZ0487 and 18SXHZ0513) and Scientific Research Project of Sichuan Health Commission (grant no. 19PJ200).

\section{Availability of data and materials}

The datasets used and/or analyzed during the current study are available from the corresponding author on reasonable request.

\section{Authors' contributions}

XLG and GCH designed the study. GCH and XWZ performed the experiments and wrote the initial draft of the manuscript. LHY, RS and JZ were involved in literature search and statistical analysis. HBL, QM, LX and DSW were involved in performing experiments. XLG reviewed and edited the manuscript. All authors read and approved the manuscript.

\section{Ethics approval and consent to participate}

Not applicable.

\section{Patient consent for publication}

Not applicable.

\section{Competing interests}

The authors declare that they have no competing interests.

\section{References}

1. Tharmapalan P, Mahendralingam M, Berman HK and Khokha R: Mammary stem cells and progenitors: Targeting the roots of breast cancer for prevention. EMBO J 15: e100852, 2019.

2. Chen W, Zheng R, Baade PD, Zhang S, Zeng H, Bray F, Jemal A, Yu XQ and He J: Cancer statistics in China, 2015. CA Cancer J Clin 66: 115-132, 2016.

3. Garrido-Castro AC, Lin NU and Polyak K: Insights into molecular classifications of triple-negative breast cancer: Improving patient selection for treatment. Cancer Discov 9: 176-198, 2019.

4. Nedeljković M and Damjanović A: Mechanisms of chemotherapy resistance in triple-negative breast cancer-how we can rise to the challenge. Cells 8: 957, 2019.

5. Kandoth C, McLellan MD, Vandin F, Ye K, Niu B, Lu C, Xie M, Zhang Q, McMichael JF, Wyczalkowski MA, et al: Mutational landscape and significance across 12 major cancer types. Nature 502: 333-339, 2013.

6. Synnott NC, Murray A, McGowan PM, Kiely M, Kiely PA, O'Donovan N, O'Connor DP, Gallagher WM, Crown J and Duffy MJ: Mutant p53: A novel target for the treatment of patients with triple-negative breast cancer?. Int J Cancer 140: 234-246, 2017.

7. Cordani M, Pacchiana R, Butera G, D'Orazi G, Scarpa A and Donadelli M: Mutant p53 proteins alter cancer cell secretome and tumour microenvironment: Involvement in cancer invasion and metastasis. Cancer Lett 376: 303-309, 2016.

8. Tan BS, Tiong KH, Choo HL, Chung FFL, Hii LW, Tan SH, Yap IK, Pani S, Khor NT, Wong SF, et al: Mutant p53-R273H mediates cancer cell survival and anoikis resistance through AKT-dependent suppression of BCL2-modifying factor (BMF). Cell Death Dis 6: e1826, 2015.

9. Muller PA and Vousden KH: Mutant p53 in cancer: New functions and therapeutic opportunities. Cancer Cell 25: 304-317, 2014.

10. Bartel DP: MicroRNAs: Target recognition and regulatory functions. Cell 136: 215-233, 2009.

11. Bertoli G, Cava C, Diceglie C, Martelli C, Rizzo G, Piccotti F, Ottobrini L and Castiglioni I: MicroRNA-567 dysregulation contributes to carcinogenesis of breast cancer, targeting tumor cell proliferation, and migration. Breast Cancer Res Treat 161: 605-616, 2017.

12. Ren Y, Chen Y, Liang X, Lu Y, Pan W and Yang M: miRNA-638 promotes autophagy and malignant phenotypes of cancer cells via directly suppressing DACT3. Cancer Lett 390: 126-136, 2017.

13. Li Z, Meng Q, Pan A, Wu X, Cui J, Wang Y and Li L: MicroRNA-455-3p promotes invasion and migration in triple negative breast cancer by targeting tumor suppressor EI24. Oncotarget 8: 19455-19466, 2017.

14. Humphries B and Yang C: The microRNA-200 family: Small molecules with novel roles in cancer development, progression and therapy. Oncotarget 6: 6472-6498, 2015.

15. Chikh A, Ferro R, Abbott JJ, Piñeiro R, Buus R, Iezzi M, Ricci F, Bergamaschi D, Ostano P, Chiorino G, et al: Class II phosphoinositide 3 -kinase $\mathrm{C} 2 \beta$ regulates a novel signaling pathway involved in breast cancer progression. Oncotarget 7: 18325-18345, 2016.

16. Noonan EJ, Place RF, Pookot D, Basak S, Whitson JM, Hirata H, Giardina C and Dahiya R: miR-449a targets HDAC-1 and induces growth arrest in prostate cancer. Oncogene 28: 1714-1724, 2009.

17. Jeon HS, Lee SY, Lee EJ, Yun SC, Cha EJ, Choi E, Na MJ, Park JY, Kang J and Son JW: Combining microRNA-449a/b with a HDAC inhibitor has a synergistic effect on growth arrest in lung cancer. Lung Cancer 76: 171-176, 2012.

18. Stojanovic N, Hassan Z, Wirth M, Wenzel P, Beyer M, Schäfer C, Brand P, Kroemer A, Stauber RH, Schmid RM, et al: HDAC1 and HDAC2 integrate the expression of p53 mutants in pancreatic cancer. Oncogene 36: 1804-1815, 2016.

19. Sun X, Liu S, Chen P, Fu D, Hou Y, Hu J, Liu Z, Jiang Y, Cao X, Cheng C, et al: miR-449a inhibits colorectal cancer progression by targeting SATB2. Oncotarget 8: 100975-100988, 2016.

20. Chen SP, Liu BX, Xu J, Pei XF, Liao YJ, Yuan F and Zheng F: miR-449a suppresses the epithelial-mesenchymal transition and metastasis of hepatocellular carcinoma by multiple targets. BMC Cancer 15: 706, 2015.

21. Luo W, Huang B, Li Z, Li H, Sun L, Zhang Q, Qiu X and Wang E: MicroRNA-449a is downregulated in non-small cell lung cancer and inhibits migration and invasion by targeting c-Met. PLoS One 8: e64759, 2013. 
22. Wei B, Song Y, Zhang Y and Hu M: MicroRNA-449a functions as a tumor-suppressor in gastric adenocarcinoma by targeting Bcl-2. Oncol Lett 6: 1713-1718, 2013.

23. Livak KJ and Schmittgen TD: Analysis of relative gene expression data using real-time quantitative PCR and the 2(-Delta Delta C(T)) method. Methods 25: 402-408, 2001.

24. Fruman DA and Rommel C: PI3K and cancer: Lessons, challenges and opportunities. Nat Rev Drug Discov 13: 140-156, 2014

25. Subramanian M, Francis P, Bilke S, Li XL, Hara T, Lu X, Jones MF, Walker RL, Zhu Y, Pineda M, et al: A mutant p53/let-7i-axis-regulated gene network drives cell migration, invasion and metastasis. Oncogene 34: 1094-1104, 2015.

26. Zhang S, Zhou L, Hong B, van den Heuvel AP, Prabhu VV, Warfel NA, Kline CL, Dicker DT, Kopelovich L and El-Deiry WS Small-molecule NSC59984 restores p53 pathway signaling and antitumor effects against colorectal cancer via p73 activation and degradation of mutant p53. Cancer Res 75: 3842-3852, 2015.

27. Jung CL, Mun H, Jo SY, Oh JH, Lee C, Choi EK, Jang SJ and Suh YA: Suppression of gain-of-function mutant p53 with metabolic inhibitors reduces tumor growth in vivo. Oncotarget 7: 77664-77682, 2016.

28. Chen T, You Y, Jiang H and Wang ZZ: Epithelial-mesenchymal transition (EMT): A biological process in the development, stem cell differentiation, and tumorigenesis. J Cell Physiol 232: 3261-3272, 2017.

29. Tao Y,Han T,Zhang T, Ma C and Sun C: LncRNA CHRF-induced miR-489 loss promotes metastasis of colorectal cancer via TWIST1/EMT signaling pathway. Oncotarget 8: 36410-36422, 2017.

30. Heerboth S, Housman G, Leary M, Longacre M, Byler S, Lapinska K, Willbanks A and Sarkar S: EMT and tumor metastasis. Clin Transl Med 4: 6, 2015.

31. Hori S, Wadhwa K, Pisupati V, Zecchini V, Ramos-Montoya A, Warren AY, Neal DE and Gnanapragasam VJ: Loss of hSef promotes metastasis through upregulation of EMT in prostate cancer. Int J Cancer 140: 1881-1887, 2017.

32. Kim T, Veronese A, Pichiorri F, Lee TJ, Jeon YJ, Volinia S, Pineau P, Marchio A, Palatini J, Suh SS, et al: p53 regulates epithelial-mesenchymal transition through microRNAs targeting ZEB1 and ZEB2. J Exp Med 208: 875-883, 2011.
33. Dong P, Karaayvaz M, Jia N, Kaneuchi M, Hamada J, Watari H, Sudo S, Ju J and Sakuragi N: Mutant p53 gain-of-function induces epithelial-mesenchymal transition through modulation of the miR-130b-ZEB1 axis. Oncogene 32: 3286-3295, 2013.

34. Hosain SB, Khiste SK, Uddin MB, Vorubindi V, Ingram C, Zhang S, Hill RA, Gu X and Liu YY: Inhibition of glucosylceramide synthase eliminates the oncogenic function of $553 \mathrm{R} 273 \mathrm{H}$ mutant in the epithelial-mesenchymal transition and induced pluripotency of colon cancer cells. Oncotarget 7: 60575-60592, 2016.

35. Raha P, Thomas S, Thurn KT, Park J and Munster PN: Combined histone deacetylase inhibition and tamoxifen induces apoptosis in tamoxifen-resistant breast cancer models, by reversing Bcl-2 overexpression. Breast Cancer Res 17: 26, 2015.

36. Shoja MH, Reddy ND, Nayak PG, Srinivasan KK and Rao CM: Glycosmis pentaphylla (Retz.) DC arrests cell cycle and induces apoptosis via caspase-3/7 activation in breast cancer cells. J Ethnopharmacol 168: 50-60, 2015.

37. You J, Zhang Y, Li Y, Fang N, Liu B, Zu L and Zhou Q: miR-449a suppresses cell invasion by inhibiting MAP2K1 in non-small cell lung cancer. Am J Cancer Res 5: 2730-2744, 2015.

38. Noonan EJ, Place RF, Basak S, Pookot D and Li LC: miR-449a causes $\mathrm{Rb}$-dependent cell cycle arrest and senescence in prostate cancer cells. Oncotarget 1: 349-358, 2010.

39. Kumar P, Sharad S, Petrovics G, Mohamed A, Dobi A, Sreenath TL, Srivastava S and Biswas R: Loss of miR-449a in ERG-associated prostate cancer promotes the invasive phenotype by inducing SIRT1. Oncotarget 7: 22791-22806, 2016.

40. Shi W, Bruce J, Lee M, Yue S, Rowe M, Pintilie M, Kogo R, Bissey PA, Fyles A, Yip KW and Liu FF: miR-449a promotes breast cancer progression by targeting CRIP2. Oncotarget 7 : 18906-18918, 2016.

This work is licensed under a Creative Commons Attribution-NonCommercial-NoDerivatives 4.0 International (CC BY-NC-ND 4.0) License. 